\title{
The use of serious games in science education: a review of selected empirical research from 2002 to 2013
}

\author{
Meng-Tzu Cheng ${ }^{1} \cdot$ Jhih-Hao Chen ${ }^{1}$ • \\ Sheng-Ju Chu' ${ }^{1}$ Shin-Yen Chen ${ }^{1}$
}

Received: 15 December 2014/Revised: 24 June 2015/ Accepted: 26 June 2015 /

Published online: 19 July 2015

(C) Beijing Normal University 2015

\begin{abstract}
This research aims to systematically review the empirical studies on the use of serious games in science education from 2002 to 2013. To this end, the Science Citation Index and the Social Science Citation Index databases were used as the literature sources and a total of 53 empirical studies were identified as the review targets. A coding scheme including three major dimensions, namely, the game, pedagogy and research method dimensions, was developed, and, with this coding scheme, a series of content analyses were conducted. These analyses identified several significant research trends among the empirical studies using serious games in science education published from 2002 to 2013, including the following: (1) a surge of interest in the use of serious games in science education was revealed; (2) adventure/role-playing games were the most popular game type used in the reviewed empirical studies; (3) knowledge construction was the major learning goal of these serious games used in science educational settings; (4) most of the reviewed studies were concerned with interdisciplinary learning; (5) relatively fewer studies explicitly introduced the educational theoretical foundations for using serious games in science education or the instructional strategies coupled with the use of serious games; (6) quantitative research designs constituted the most commonly used research approach; and (7) a majority of the reviewed studies focused on investigating the effectiveness of serious games from the perspective of cognitive outcomes. The educational implications and directions for further research derived from the findings of this study are further discussed.
\end{abstract}

Keywords Serious games - Science education - Game · Pedagogy · Content analysis research method

Meng-Tzu Cheng

mtcheng@cc.ncue.edu.tw

1 Department of Biology, National Changhua University of Education, No.1, Jinde Rd., Changhua City, Changhua County, Taiwan 


\section{Introduction}

It goes without saying that the enormous prosperity of today's gaming industry reveals that play and technology have been combined in interesting ways; a large number of players find video games to be highly enjoyable and are willing to invest considerable time and effort in playing them (Entertainment Software Association 2013). The stereotype of video games has been subverted, as video games are no longer regarded as merely a form of entertainment. The level of interest in developing new and innovative tools to support learning has increased rapidly in recent years as the use of video games for educational purposes has gradually attracted more and more attention from educators and researchers, and as the positive impact of video games on learning has seemed increasingly promising (Connolly et al. 2012; Gee 2003a, b; Paraskeva et al. 2010; Prensky 2001). This is especially true for science education given that the use of video games to enhance science learning has gradually become quite prevalent since the serious games movement was initiated in 2002 (Annetta et al. 2009; Annetta et al. 2009; Barab et al. 2005; Cheng and Annetta 2012; Cheng et al. 2011; Squire et al. 2004). In general, it is believed that video games can offer virtual environments in which players can become absorbed and engaged in the embedded science learning activities, such that they carry out the tasks with considerable enjoyment and fulfilment. With that in mind, the purpose of this study is to systematically review the empirical studies on the use of video games in science education from 2002 to 2013.

This review starts by clarifying the difference between the terms, games, video games and serious games. Accordingly, the importance of serious games in science education is discussed. After introducing the research questions, methods including the selection of articles and the framework of coding scheme are described. Then, the results are reported, followed by the discussion and conclusions. It is hoped that this study can provide us with a better understanding of how video games have been used and thus provide deeper insights into the further potential of video games for supporting science learning.

\section{Games, video games and serious games}

Before thoroughly investigating the available evidence on using serious games in science education, we have to clarify several terms that frequently confuse people (Zyda 2005). Game is a broad concept that refers to all structured play consisting of rules, goals and challenges that are undertaken for diversion or amusement. The emergence of game mechanisms can be traced back to $3000 \mathrm{BC}$, when the earliest dice were created (Radoff 2011). Since then, games have come in many varieties and settings, and video games are one broad type of game that has burgeoned at an astronomical pace over the past five decades. The term video game refers to an electronic game involving a variety of images controlled by players. Such games can be played through vehicles such as computers, arcades, consoles and mobile phones and may involve visual displays of virtual reality (VR) and mixed reality 
(MR) including augmented reality (AR) and augmented virtuality (AV) (Milgram and Kishino 1994). Video games are displayed as 2D or 3D images and are manipulated by a single player or multiple players. The terms digital games, computer games, web-based games, and online games are typically considered to be synonymous with video games and are generally used interchangeably with video games in the literature and in the present study. Video games are generally categorized into eight genres including action, adventure, fighting, puzzle, roleplaying, simulation, sport and strategy games, although these genres often overlap (Prensky 2001). Serious game, a term which was first introduced by Abt (1970), refers to games that have "an explicit and carefully thought-out educational purpose and are not intended to be played primarily for amusement." At the time, the term was primarily used in regard to board games and card games, and it did not come into widespread use until the emergence of the Serious Games Initiative in 2002, which attempts to harness the power of video games for non-entertainment purposes. Nowadays, serious game has become a popular and particular term referring to any kind of video game-based learning and trainings (e.g. business, military, medical, marketing, etc.) or the so-called "edutainment" (Susi 2007). Serious games involve both formal and informal settings, and their target audiences include all ages. Annetta (2008) has further defined certain serious games as serious educational games (SEG) in order to distinguish serious games in general from nonentertainment games specific to K-20 educational settings. Figure 1 shows the relationship between games, video games, serious games and SEG.

\section{Serious games in science education}

More and more researchers and educators have made an effort to integrate serious games into classrooms since the serious games movement was initiated (Annetta

Fig. 1 The relationships between games, video games, serious games and serious educational games

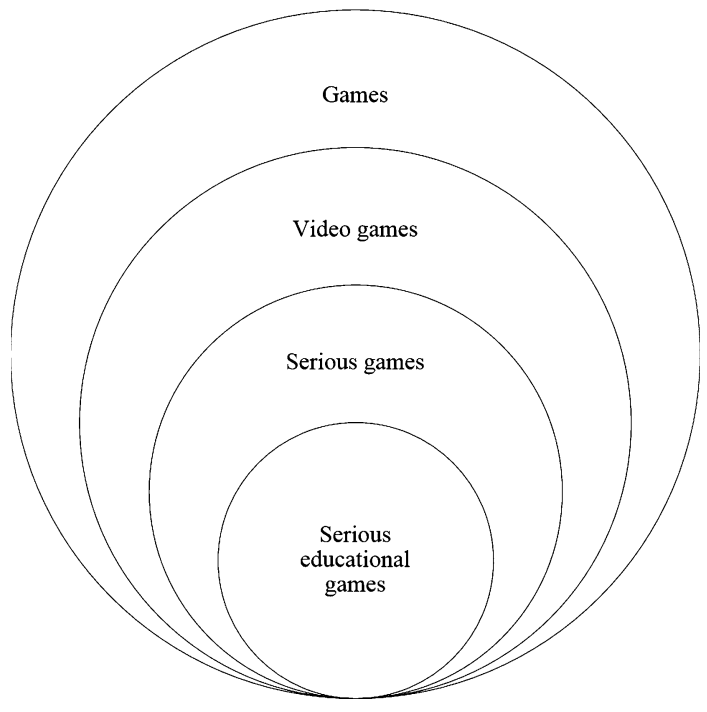


2008; Connolly et al. 2012). Since serious games create a virtually immersive context wherein students are allowed to experience things and repeat experimentations that are unlikely to be realized in their daily lives, it is believed that their use in educational settings can increase the probability of providing students with authentic learning (Cheng and Annetta 2012; Susi 2007). Moreover, it is hoped that the use of such games can improve student learning motivation (e.g. Papastergiou 2009), facilitate knowledge acquisition (e.g. Miller et al. 2011), increase task engagement (e.g. Annetta et al. 2009), and foster specific abilities such as problem solving and collaboration (e.g. Sánchez and Olivares 2011) by appropriately visualizing abstract ideas and key principles of given topics in the game environment. To this date, many empirical studies have been conducted to examine the effectiveness of serious games (Connolly et al. 2012).

Scientific concepts are more abstract and complicated compared to those of other disciplines; therefore, students generally have a sense of anxiety and various difficulties in science learning. Moreover, scientific inquiry and problem-solving skills often require long-term cultivation and repeated practice. The meaningful understanding of science requires students to be able to apply scientific concepts and principles to solve problems in a variety of situations and unfamiliar contexts (Cheng et al. 2014). However, traditional views of science education that employ behaviouristic approaches in teaching and that mainly focus on fact memorization and rote learning do not really fit the needs of today's learners (Pursell 2009). The emergence of serious games undoubtedly brings a huge opportunity for science education and holds the potential not only to help learners construct accurate intuitive understandings of science but also to prepare them for future learning through a more flexible and powerful method of instruction (Clark et al. 2009). In the past decade, serious games have been widely used to facilitate the learning of biology (e.g. Cheng et al. 2011), physics (e.g. Annetta et al. 2009), and so forth. As such, an in-depth review regarding what studies have been done and how they have been conducted is of substantial importance for providing science educators, instructors and researchers with deeper insights into the relationships between serious games and science education. Only when we thoroughly examine these past studies and utilize the information included in them will we know the direction that future research and instructional efforts should take. However, although the effectiveness of serious games has been reviewed in some previous studies, systematic reviews specifically tackling the issue of using serious games in science education are relatively lacking.

Connolly et al. (2012) reviewed 129 empirical papers related to the impacts and outcomes of gaming published from 2004 to 2009. They found that knowledge acquisition/content understanding and affective and motivational outcomes were the main focus of the reviewed articles. However, they emphasized the use of serious games in a wide range of subjects, and only 11 of the reviewed studies were about science learning. Young et al. (2012) identified over 300 articles related to serious gaming; they concluded that serious gaming might be effective for history and language learning and physical education, yet little support for science-based serious gaming was revealed. They further indicated, however, that the potential for using serious games in science learning has yet to be fully explored and that more 
efforts should be devoted to exploring that potential. They further stated that the aspect of deeper understanding rather than superficial comprehension should be examined to reveal the actual impact of serious games on science learning. In their study, academic achievement was the main concern, and only 11 science video gaming studies were discovered. A study by Hwang and Wu (2012), meanwhile, reviewed 137 papers published from 2001 to 2010. As that review was a colloquium article, it simply reported the number of the published articles, the selected research sample groups, the selected research learning domains, and the major contributing countries, and only 14 publications about science-based serious gaming were found. A later review by $\mathrm{Li}$ and Tsai (2013) might be the only available research thus far which has focused on using serious games in science education. A total of 31 empirical articles related to game-based science learning published from 2000 to 2011 were identified in their study. They placed their stress on research purposes and designs, game designs and implementations, and theoretical foundations and learning foci of the selected articles using a qualitative content analysis technique. The findings revealed that most of these articles aimed at using serious games to facilitate scientific knowledge acquisition, while only a few studies focused on problem-solving skills or the aspects of affect, engagement and socio-contextual learning.

Researchers generally agree that serious games can be an effective and powerful tool for science learning because of their unique capacity for combining serious subject matter with enjoyment. The review by Li and Tsai (2013) undoubtedly provides us with valuable information with respect to how serious games have been used for facilitating student science learning; however, there still seem to be some missing pieces that were not revealed in their study. Therefore, the present study, building on the results of the work by Li and Tsai (2013), attempts to propose a thorough framework consisting of three dimensions, namely, game, pedagogy and research method, and uses this framework as a lens through which the available published literature related to the use of serious games in science education could be systematically reveiwed.

\section{Research questions}

In this study, we thoroughly examine the previous empirical studies in terms of the aforementioned three dimensions of game, pedagogy and research method in order to get a complete picture of the advancements and trends in using serious games (SGs; for convenience, "serious game" and its abbreviation, SG, are used interchangeably in this study) in science education from 2002 to 2013. To this end, the following three main research questions are addressed:

(1) What are the game features of the reviewed SGs?

(2) What are the pedagogical concerns that the studies using SGs in science education emphasized?

(3) What methodology was used in the studies using SGs in science education? 


\section{Method}

\section{Research papers used for analyses}

This study aims to conduct a systematic literature review of empirical research on the use of SGs in science education from 2002, when the Serious Games Initiative commenced, to 2013. To this end, the Science Citation Index (SCI) database and Social Science Citation Index (SSCI) database were used as the sources of literature for review in this study. The SCI database and the SSCI database are two highly recognized databases that index core journals in both educational technology and science education. By limiting the search to the SCI database and the SSCI database, only empirical studies published from 2002 to 2013 in journals were selected. Conference proceedings, unpublished dissertations, books and book chapters were thus excluded from the review.

The research papers selected for the review in this study were identified by means of the two following procedures. First, the researchers searched the SCI database and the SSCI database using keywords. To be included in the review targets, each study needed to include at least one keyword regarding science education, and at least one keyword related to digital games. The keywords for science education included science learning, learning science, science teaching or teaching science, science education, science instruction, biology learning, chemistry learning, physics learning, biology teaching, physics teaching, chemistry teaching, biology education, physics education, chemistry education, biology instruction, physics instruction and chemistry instruction. The keywords related to digital games included educational game, gaming, digital game, game-based learning, DGBL, digital game-based learning, on-line game, online game, computer game, video game and serious game. The two sets of keywords were combined using the Boolean logic term "AND", and a total of 88 journal papers published from 2002 to 2013 were selected. Then, the researchers manually and systematically screened the article titles and abstracts and confirmed that the selected articles: (1) used serious game(s) for learning or teaching; (2) were related to science education; and (3) were empirical studies. Articles not meeting those three criteria were excluded. Finally, a total of 53 empirical studies were identified as the sample pool for the review.

\section{The framework of the coding scheme}

After identifying the studies for review, the framework for a coding scheme was established by three science education researchers through an iterative process of repeatedly reviewing these articles and engaging in discussion. It is believed that in an empirical study regarding the use of SGs in science education, there are three major foci for researchers: the serious game used, the pedagogical practices coupled with the use of the serious game, and the research method. Hence, to provide insights into the research on the use of SGs in science education, the framework of the coding scheme consisted of three major dimensions: the game dimension, pedagogy dimension and research method dimension. Each dimension additionally 
included several sub-dimensions and categories that were generated by a grounded theory method consisting of an inductive approach in which categories were formed through constant comparisons of the articles.

Another two researchers then coded the 53 articles using the framework as a lens through which to conduct a systematic content analysis. The inter-rater reliability between the two coders was 0.88 and consensus discussions were held to negotiate disagreements. The framework is described below.

\section{Game dimension}

This dimension focuses on examining the game features of the SGs themselves. So, the game features of the SG(s) used in the empirical study were analysed in terms of the following six aspects:

Game type According to Alessi and Trollip (2001), Prensky (2001) and Squire (2003), as well as referring to the current game genres used by Google play and Apple's app store, this study categorized the SGs in the reviewed papers into seven categories: adventure game or role-playing game, simulation game, puzzle game, strategy game, action game, fighting game or platform. The categorization is mainly based on the differences in gameplay interactions rather than those in visual displays or devices. The definitions of these seven game types are shown below.

(1) Adventure/role-playing game a game in which the player assumes the role of an in-game character in a fictitious, narrative context to accomplish an overall goal.

(2) Simulation game a game that copies various real-life activities, phenomena, or mechanisms, with the rules attempting to simulate reality for training and learning (e.g. a surgery simulation game).

(3) Puzzle game a game that requires the player to solve a variety of wellstructured problems to succeed (e.g. Sudoku).

(4) Strategy game a non-structured game in which the outcome is highly driven by the autonomous decision making and planning of the player (e.g. a business game).

(5) Action game a game that highly emphasizes hand-eye coordination and realtime action (e.g. a shooting game).

(6) Fighting game a game that requires the player to control a character that engages in combat with an opponent.

(7) Platform a serious game that is basically used as a platform for designing another game, such that it is not a playable game itself.

Player design The player design of each SG was categorized as either a single player design or a multiple player design.

Game design purpose According to whether an SG was designed specifically for science education or not, game design purposes were divided into for science education and for non-science education.

Game development If the SG was specially developed for the study, it was categorized as self-developed, which denotes that the SG was developed by the 
authors of the reviewed study themselves; otherwise, it was coded as not selfdeveloped.

Game vehicle The vehicle for delivery of an SG was categorized as computer, mobile or video console.

Game learning goal The learning goals of the SGs were categorized using a grounded theory method. It was found that the reviewed SGs were generally developed with attempts to improve the learner's concept understanding (categorized as knowledge construction), foster the learner's problem solving (problemsolving ability) or enhance the learner's collaboration skills (collaborative skills).

\section{Pedagogy dimension}

This dimension focuses on examining the pedagogical concerns. So the pedagogical practices coupled with the use of the serious game or games were analysed in terms of the following four aspects:

Subject domain The subject domains covered by the serious games used in the reviewed studies were grouped into five sub-categories: physics, chemistry, biology, earth science and interdisciplinary. If a study involved more than one subject domain, the subject domain was coded as interdisciplinary.

Educational theoretical foundation The educational theoretical foundations for using SGs revealed in the reviewed studies were classified into six categories by grounded theory analysis: constructivism, cognitive theories (including cognitive load theory, flow theory, and multimedia learning theory), Vygotsky's theories (including social presence, play, scaffolding, and ZPD), situated learning theory, activity theory and enactivism.

Instructional strategy coupled with using serious game The SGs themselves might be developed with certain goals; however, they can often be used together with other instructional strategies in educational settings. Therefore, the instructional strategies coupled with using the SGs were categorized using grounded theory analysis. Six strategies were revealed: collaborative learning, inquiry-based learning, problem solving, learning by designing, prediction-observation-explanation (POE), and self-explanation.

Pedagogical role of serious game The pedagogical roles of the serious games were also categorized using grounded theory analysis. Three pedagogical roles of the reviewed SGs were found: learning environment indicated that the SG was used to provide learning contexts for the whole science learning activities; instructional tool denoted that the SG was considered as a part of learning activities in the whole instructional unit; and assessment indicated that the SG was used to conduct formative or summative assessments.

\section{Research method dimension}

The research methodology of an empirical study regarding the use of serious games was analysed in terms of the following three aspects:

Participants According to the academic levels of the context in which each study was conducted, the participants were categorized according to the following 
categories: pre-school (or kindergarten), elementary school (i.e. grades 1-6), junior high school (i.e. grades 7-9), senior high school (i.e. grades 10-12), university or college, and others (such as in-service teachers).

Research method According to its research method, each reviewed study was allocated to one of the following three categories: quantitative research, in which only quantitative research methods were used; qualitative research, in which only qualitative research methods were used; or mixed-method research, in which both qualitative and quantitative research methods were used.

Research foci The research foci of all the selected studies were divided into three major categories: cognitive outcomes, affective outcomes and learning processes. A study with research focusing on "cognitive outcomes" explores participants' recall of information or acquisition of knowledge or skill; a study addressing "affective outcomes" examines perceptions or attitudes towards learning and learning materials, motivation towards science careers, or satisfaction with the instructional activities; and a study focusing on "learning processes" investigates learning approaches used by students or interactions between students. It should be noted that a reviewed study might contain more than one research focus.

\section{Results}

\section{Numbers of studies published and major contributing journals}

Figure 2 shows the number of empirical studies regarding the use of SGs in science education published from 2002 to 2013. As shown in Fig. 2, out of the 53 empirical studies, only 4 articles were published from 2002 to 2006 . On the other hand, the number of published articles displayed a sharp increase from 2007 to 2011, with a total of 27 studies published during that period, and from 2012-2013, during which an additional 22 articles were published. In particular, a total of 40 articles were published from 2011 to 2013 (Fig. 3). These results imply that the potential of SGs in science education has evoked even more attention from researchers and educators

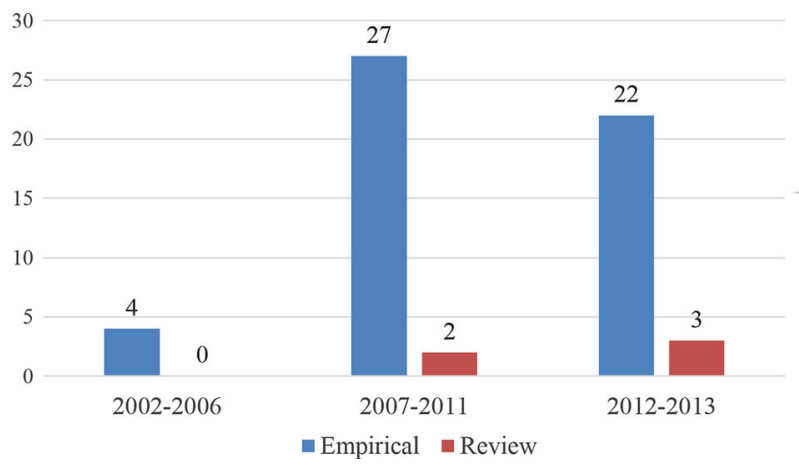

Fig. 2 Numbers of publications by selected intervals from 2002 to 2013 


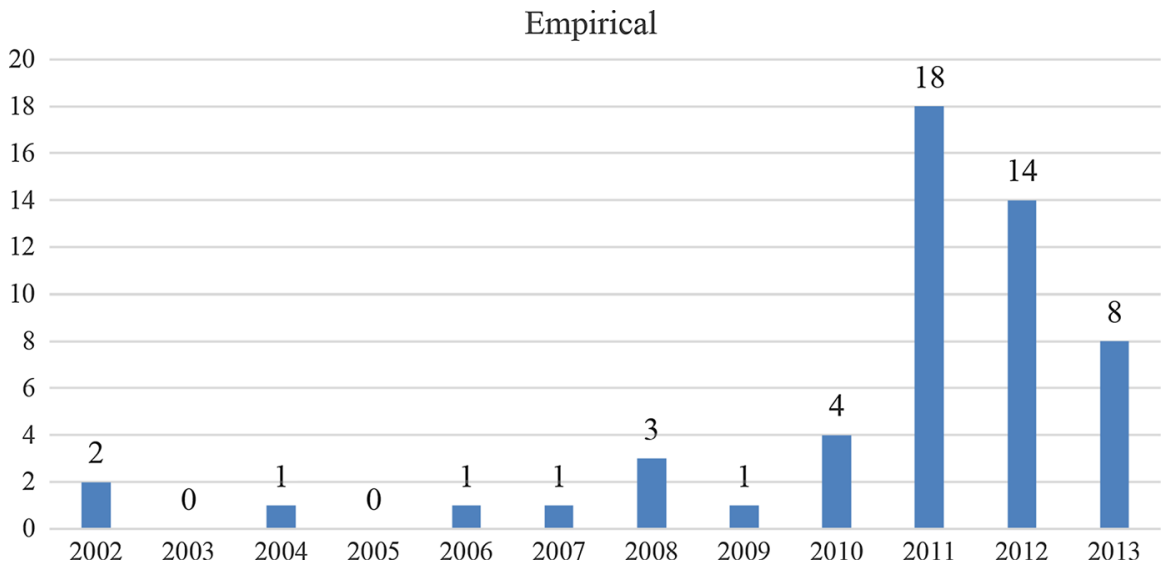

Fig. 3 Numbers of empirical studies published each year from 2002 to 2013

in recent years and that, as a result, an increasing amount of research has been conducted to investigate the effectiveness of serious games in science learning recently.

Table 1 presents the top seven contributing journals. According to Table 1, most of the relevant studies were published in Computers and Education (21 studies). It should be noted that, among these top seven journals, only the Journal of Science Education and Technology and CBE-Life Science Education are science educationrelated journals. In other words, relatively few studies of this sort were published in science educational journals from 2002 to 2013.

\section{Game dimension}

Game type of the SGs used in the reviewed studies

Table 2 demonstrates that the most popular game type among the SGs was "adventure or role-playing game" (29 studies), followed by "simulation game" (11 studies) and "puzzle game" (6 studies). The frequent use of adventure or roleplaying games in improving students' science learning outcomes is considerably in

Table 1 Top seven

contributing journals in terms of the number of empirical studies published on using SG in science education from 2002 to 2013

Three journals were tied for fifth
place

\begin{tabular}{llc}
\hline Rank & Journal title & $N(\%)$ \\
\hline 1 & Computers and Education & $21(40)$ \\
2 & Journal of Science Education and Technology & $6(11)$ \\
3 & Journal of Computer Assisted Learning & $4(8)$ \\
4 & Journal of Educational Computing Research & $3(6)$ \\
5 & British Journal of Educational Technology & $2(4)$ \\
5 & CBE-Life Science Education & $2(4)$ \\
5 & Computers in Human Behavior & $2(4)$ \\
\hline
\end{tabular}


Table 2 Game types of the SGs used in reviewed studies from 2002 to 2013

\begin{tabular}{lllll}
\hline Game type & $2002-2006$ & $2007-2011$ & $2012-2013$ & Total \\
\hline Adventure or role-playing game & 2 & 15 & 12 & 29 \\
Simulation game & 2 & 3 & 6 & 11 \\
Puzzle game & 0 & 4 & 2 & 6 \\
Strategy game & 0 & 1 & 0 & 1 \\
Action game & 0 & 2 & 0 & 2 \\
Fighting game & 0 & 0 & 0 & 0 \\
Platform & 0 & 2 & 2 & 4 \\
\hline
\end{tabular}

alignment with the results of previous research (Chung and Wu 2011). Moreover, it should also be noted that four relevant studies used platform SGs for developing games in recent years (i.e. 2007-2013). In these studies, project-based learning was often employed, and the participants were not merely regarded as SG players but also as SG designers. Educational researchers have advocated that "learning by designing" might provide students with more opportunities to learn and train their 21 st century skills through the process of designing (e.g. Annetta and Cheng 2008). It seems that SG researchers have highlighted the aforementioned perspective.

\section{Player design of the SGs used in the reviewed studies}

Among the 53 reviewed studies, four studies used SGs as a platform. Thus, those four SG studies were excluded in this part of the analysis. As shown in Table 3, a single-player design was used in 31 of the remaining studies, while 18 studies used SGs with a multi-player game design.

\section{Game design purposes of the SGs used in the reviewed studies}

Table 4 reveals that, during the period of 2002-2013, the SGs used in the relevant studies were originally designed either for non-science education or for science education. However, SGs specifically designed for science education were used in a majority of the empirical SG-related studies $(n=45)$, while relatively fewer studies used SGs that were designed for non-science education $(n=8)$.

Table 3 Player designs of SGs in the reviewed studies from 2002 to 2013

\begin{tabular}{lllll}
\hline Player designs & $2002-2006$ & $2007-2011$ & $2012-2013$ & Total \\
\hline Single-player design & 2 & 13 & 16 & 31 \\
Multi-player design & 2 & 12 & 4 & 18 \\
\hline
\end{tabular}

The four SG-related studies in which games were used as platforms were excluded 
Table 4 Game design purposes of SGs in the reviewed studies from 2002 to 2013

\begin{tabular}{llccr}
\hline Game design purposes & $2002-2006$ & $2007-2011$ & $2012-2013$ & Total \\
\hline Designed for non-science education & 1 & 6 & 1 & 8 \\
Designed for science education & 3 & 21 & 21 & 45 \\
\hline
\end{tabular}

Game development of the SGs used in the reviewed studies

According to Table 5, both SGs developed by the study authors themselves (32 studies) and those developed by other researchers (16 studies) were utilized in the reviewed SG-related studies. However, the number of studies using self-developed SGs was about two times the number of those employing non-self-developed SGs.

\section{Game vehicle of the SGs used in the reviewed studies}

As shown in Table 6, computers were the most frequently used game vehicle for the SGs in the relevant studies (49 studies), followed by mobile devices (3 studies) and video consoles (1 study). Furthermore, only computer games were used in the SGrelated studies published from 2002 to 2006, while both computer and mobile games were utilized from 2007 to 2013, and the only SG that used video consoles as the game vehicle was published during the 2012-2013 period. In addition, when we looked into what kind of visual displays these SGs employed, we found that most of them were created with VR display and AR was used since 2007. It seems that various game vehicles and MR that add virtual elements to a real environment have been used in SG-based science education during the past few years.

\section{Game learning goal of the SGs used in the reviewed studies}

A majority of the learning goals of the SGs used in the reviewed studies (43 studies) focused on student knowledge construction, followed by problem-solving ability (12 studies) and collaboration skills (2 studies) (Table 7). The results indicate that prompting learners' understanding of scientific concepts was the most common learning goal. However, only knowledge construction and problem-solving ability were revealed as the learning goals of the SGs used in the reviewed studies published from 2002 to 2006, while knowledge construction, problem-solving ability and collaboration skills were revealed as goals in the SG-related studies

Table 5 Game development of SGs in the reviewed studies from 2002 to 2013

\begin{tabular}{lllll}
\hline Game development & $2002-2006$ & $2007-2011$ & $2012-2013$ & Total \\
\hline Self-developed SGs & 3 & 15 & 15 & 33 \\
Not self-developed SGs & 1 & 10 & 5 & 16 \\
\hline
\end{tabular}

The four SG-related studies in which games were used as platforms were excluded 
Table 6 Game vehicle of the SGs used in the reviewed studies from 2002 to 2013

\begin{tabular}{llccr}
\hline Game vehicle & $2002-2006$ & $2007-2011$ & $2012-2013$ & Total \\
\hline Computer & 4 & 17 & 18 & 39 \\
Mobile device & 0 & 3 & 1 & 4 \\
Video console & 0 & 5 & 1 & 6 \\
\hline
\end{tabular}

The four SG-related studies in which games were used as platforms were excluded

Table 7 Game learning goals in the SG-related studies published from 2002 to 2013

\begin{tabular}{llcrr}
\hline Game learning goals & $2002-2006$ & $2007-2011$ & $2012-2013$ & Total \\
\hline Knowledge construction & 4 & 21 & 18 & 43 \\
Problem-solving ability & 3 & 8 & 1 & 12 \\
Collaboration skills & 0 & 2 & 0 & 2 \\
\hline
\end{tabular}

Multiple game learning goals might be revealed in an SG-related study

published since 2007. This indicates that various learning goals have been considered when designing SGs during the last decade.

\section{Pedagogy dimension}

\section{Science subject domain for SGs}

The results shown in Table 8 reveal that most of the SG-related studies published from 2002 to 2013 were concerned with interdisciplinary learning (23 articles). In addition, among the domain-specific SG-related studies, 11 studies were related to physics and 15 were focused on biology learning. However, none of the empirical SG-related studies focused on investigating the use of SGs in chemistry or earth science learning. As such, the question of how to use serious games to promote students' chemistry and earth science learning is worthy of more attention in the future.

Table 8 Science domains revealed in the reviewed SG studies from 2002 to 2013

The four SG-related studies in which games were used as platforms were excluded

\begin{tabular}{llllr}
\hline Science domains & $2002-2006$ & $2007-2011$ & $2012-2013$ & Total \\
\hline Physics & 2 & 7 & 2 & 11 \\
Chemistry & 0 & 0 & 0 & 0 \\
Biology & 0 & 8 & 7 & 15 \\
Earth science & 0 & 0 & 0 & 0 \\
Interdisciplinary & 2 & 10 & 11 & 23 \\
\hline
\end{tabular}




\section{Educational theoretical foundations of using SGs}

With the use of grounded theory method, this study reveals that, among the 53 published papers, 25 papers $(47 \%)$ did not mention any theoretical foundations for using SGs, while the other 28 studies $(53 \%)$ did introduce their theoretical foundations for using $\mathrm{SG}$ in science education. We further categorized the theoretical foundations introduced in those studies, and they are summarized in Table 9. As shown there, constructivism (7 studies) and Vygotsky's theories (including social presence, play, scaffolding and ZPD) (10 studies) were the most frequently used theoretical foundations underpinning the use of SGs in the relevant studies. It should also be noted that a greater variety of educational theories were gradually used in the relevant studies published from 2007 to 2013. In particular, cognitive theories (including cognitive load theory, flow theory and multimedia learning theory) and activity theory received considerable attention from researchers during that period.

\section{Instructional strategies coupled with using SGs}

Similarly, grounded theory analysis was used to categorize the instructional strategies coupled with the use of SGs. It was found that, among the 53 published papers, about half of the studies did not introduce any instructional strategies coupled with their use of SGs $(n=28)$, while the other 25 studies did mention their instructional strategies. As detailed in Table 10, problem solving (10 studies) was the instructional strategy that was used most frequently in general, followed by collaborative learning ( 8 studies), inquiry-based learning (6 studies), and learning by designing (4 studies). It should be acknowledged that only three kinds of instructional strategies, i.e. inquiry-based learning, problem solving and collaborative learning, were coupled with the use of SGs in the studies published from 2002 to 2006. For those studies published from 2007 to 2013, various instructional strategies were gradually coupled with the use of SGs in science education. In

Table 9 The theoretical foundations revealed in the reviewed SG-related studies from 2002 to 2013

\begin{tabular}{|c|c|c|c|c|}
\hline Theoretical foundations & 2002-2006 & 2007-2011 & 2012-2013 & Total \\
\hline Constructivism & 1 & 3 & 3 & 7 \\
\hline $\begin{array}{l}\text { Cognitive theories (including cognitive load theory, } \\
\text { flow theory and multimedia learning theory) }\end{array}$ & 0 & 3 & 2 & 5 \\
\hline $\begin{array}{l}\text { Vygostsky's theories (including social presence, play, } \\
\text { scaffolding and ZPD) }\end{array}$ & 2 & 4 & 4 & 10 \\
\hline Situated learning theory & 0 & 1 & 1 & 2 \\
\hline Activity theory & 0 & 2 & 1 & 3 \\
\hline Enactivism & 0 & 1 & 0 & 1 \\
\hline
\end{tabular}

More than one educational theory may be used in one reviewed SG-related study 
Table 10 Instructional strategies coupled with using serious games in the reviewed SG-related studies from 2002 to 2013

\begin{tabular}{llllr}
\hline Instructional strategies & $2002-2006$ & $2007-2011$ & $2012-2013$ & Total \\
\hline Collaborative learning & 2 & 5 & 1 & 8 \\
Inquiry-based learning & 2 & 4 & 0 & 6 \\
Problem-solving ability & 1 & 6 & 3 & 10 \\
Learning by designing & 0 & 2 & 2 & 4 \\
POE & 0 & 1 & 1 & 2 \\
Self-explanation & 0 & 1 & 1 & 2 \\
\hline
\end{tabular}

More than one instructional strategy may be used in one reviewed SG-related study

Table 11 Pedagogical roles of SGs in the reviewed studies published from 2002 to 2013

\begin{tabular}{llccr}
\hline Pedagogical role & $2002-2006$ & $2007-2011$ & $2012-2013$ & Total \\
\hline Learning environment & 3 & 11 & 18 & 32 \\
Instructional tool & 1 & 5 & 4 & 18 \\
Assessment & 0 & 1 & 0 & 1 \\
\hline
\end{tabular}

The four SG-related studies in which games were used as platforms were excluded, and two studies used SGs as a learning environment as well as an instructional tool

particular, learning by designing, POE strategy and self-explanation began to receive attention from researchers in the past few years (2007-2013).

\section{Pedagogical role of serious games}

This study further analysed the pedagogical roles of the SGs used in the reviewed studies. According to Table 11, the main pedagogical roles which the SGs usually served to fill were "learning environment" (32 studies) and "instructional tool" (18 studies), implying that researchers often consider SGs to function either as a learning environment that provides context supporting the whole learning activity or as an instructional tool to be utilized as a part of the learning activity. Only one study utilized SGs as a formative assessment system during the 2007-2011 period. It thus seems that while SGs may play different roles in improving students' science learning, researchers are still used to seeing them as a form of learning environment or instructional tool, rather than as assessments.

\section{Research method dimension}

\section{Participants}

It was found that most of the reviewed SG-relevant studies targeted elementary (17 studies) and junior high school students (16 studies) (Table 12). However, the data shown in Table 12 also indicate that although elementary and junior high school students were still the main target audiences, more research findings have begun to 
attach importance to the use of SGs for facilitating senior high school or college student learning since 2007. Studies that aimed to reach pre-service and in-service teachers and adults were also found in articles from 2007 to 2013. The above findings suggest that SGs are no longer thought of only as teaching and learning tools for formal education; rather, they are increasingly viewed as being potentially useful in informal settings, in addition to potentially being beneficial for teachers' professional development and for adult education.

\section{Research methods employed by SG-relevant articles}

The differences in the methods used in the relevant studies were also noted. Table 13 shows that the most commonly used research method in SG-relevant studies was a quantitative research design, which was employed in 31 of the 53 studies. The next was a mixed-method research design, which was used in 14 articles. A relatively small number of studies (8) employed a qualitative approach. These results indicate that SG researchers tended to adopt quantitatively statistical analysis combined with interviews or observations to further depict user perceptions and motivations and to examine the degree of player engagement through SG play. Among the studies that employed a mixed-methods approach, qualitative results were usually considered to serve as in-depth evidence supporting quantitative consequences. However, the results in the table also indicate that pure qualitative methods have been adopted by SG-relevant studies much more often since 2007, implying that researchers have recently begun to lay more stress on the individual differences in learning caused by serious gaming.

\section{Research foci}

This study also analysed the research foci of all the selected studies. As shown in Table 14, the majority of the reviewed studies focused on cognitive outcomes (42 studies) as a part of or as the only research outcomes, and relatively few studies explored students' affective outcomes (24 studies) or learning processes (11 studies). These findings suggest that future research should focus not only on participants' cognitive learning outcomes but also on their learning processes and affective aspects.

Table 12 Target audience of the reviewed studies published from 2002 to 2013

Studies that reached multiple target audience levels were counted repeatedly

\begin{tabular}{llllc}
\hline Target students & $2002-2006$ & $2007-2011$ & $2012-2013$ & Total \\
\hline Pre-school & 0 & 2 & 0 & 2 \\
Elementary school & 2 & 7 & 8 & 17 \\
Junior high school & 0 & 12 & 4 & 16 \\
Senior high school & 2 & 2 & 5 & 9 \\
College & 0 & 6 & 3 & 9 \\
Others & 0 & 2 & 3 & 5 \\
\hline
\end{tabular}


Table 13 Research methods employed in the reviewed SG-related studies from 2002 to 2013

\begin{tabular}{llcrr}
\hline Research methods & $2002-2006$ & $2007-2011$ & $2012-2013$ & Total \\
\hline Quantitative research & 2 & 11 & 18 & 31 \\
Qualitative research & 0 & 6 & 2 & 8 \\
Mixed-method research & 2 & 10 & 2 & 14 \\
\hline
\end{tabular}

Table 14 Research foci of the reviewed studies published from 2002 to 2013

\begin{tabular}{lllll}
\hline Research foci & $2002-2006$ & $2007-2011$ & $2012-2013$ & Total \\
\hline Cognitive outcomes & 4 & 21 & 17 & 42 \\
Affective outcomes & 3 & 10 & 11 & 24 \\
Learning process & 1 & 7 & 3 & 11 \\
\hline
\end{tabular}

An SG-related study might have more than one research focus

\section{Discussion}

This study aimed to provide insights into empirical research regarding the use of SGs in science education. To this end, selected empirical studies published from 2002 to 2013 were systematically reviewed through a specific framework consisting of the following three dimensions: the game dimension, the pedagogy dimension and the research method dimension. Major findings derived from this study are discussed below.

An increasing trend in the amount of SG-related studies was revealed. The present study is essentially consistent with other related studies (Connolly et al. 2012; Hwang and Wu 2012), inasmuch as the study results confirmed a surge of interest in the use of SGs in science education over the past decade. These findings are encouraging because they indicate that a better understanding of what SGs offer to science learning, as well as how they accomplish their effects, will be gained relatively soon as more and more research is focused on investigating the effectiveness of using SGs in science education. What is surprising, however, is that the majority of the available studies were published in digital learning-related journals, while only a few studies were published in journals dealing specifically with science education, even though most of the games used were actually designed for science learning. It seems that the number of science educators involved in using SGs for science learning is still relatively low, such that most of the available studies were likely conducted by researchers whose specialty is digital learning, not science education. The finding further supports this conclusion that only a few science learning-specific strategies, e.g. inquiry-based learning and predict, observe, explain (POE) $(n=8)$ were adopted in the reviewed SG-related studies (Table 10). Moreover, 28 out of the 51 reviewed studies did not introduce the instructional 
strategies coupled with their use of SGs. However, as more SGs can be freely obtained now, the current and future foci of research regarding the use of SGs in science education should be not only on developing new games for science learning, but also on examining how those games which are already available can be successfully integrated into classrooms. Thus, as advocated by Echeverría et al. (2011), instructional strategies (or pedagogical models) will be of increasing importance. In other words, when it comes to the use of SGs in classrooms, the instructional strategies used by instructors may prove crucial for the success of integrating a given SG into a given class. Therefore, in order to obtain deeper insights into the way SGs can be used in science classes and how they can support science learning, more science educators need to be involved in designing and implementing SG-related instructions.

Not surprisingly, this study represents that adventure or role-playing games constituted the most popular game type among the SGs used in the reviewed studies. Because adventure/role playing games empower students to construct identities in virtual worlds by customizing their own avatars, these in-game avatars serve as the vehicle through which students can interact with authentic learning environments directly (Barab et al. 2005). For science educators, improving student inquiry abilities is crucial. The use of avatars, therefore, allows students to participate in inquiry activities and to explore different tasks embedded in the game environment repeatedly. Besides, adventure/role-playing games might more easily provide students with the experience of immersion (Brown and Cairns 2004; Cheng et al. 2014), which has been evidenced to play an important role in facilitating student engagement and learning (Dede 2009). It is suggested that further research should be conducted to explore the roles that avatars play in students' SG-related learning processes. One thing regarding game classifications should be acknowledged. To date, there actually exist many different classifications of games. However, in this study, serious games were classified into only seven categories because what we are interested in is the gameplay interactions that the game provides to facilitate science learning. For example, although there are 17 different categories of games in iTunes Apple Store, some of them, such as dice, casino, music, etc., are not suitable for the use in science education, so the categories were simplified and reduced. This taxonomy based on Alessi and Trollip (2001), Prensky (2001) and Squire (2003) as well as referring to the current game genres used by Google play and Apple's app store might be outdated, yet it remains classic when it comes to the research related to game-based learning.

This study also reveals that researchers have placed substantial emphasis on social interactions, as about one third of the games used had a multi-player design. This may be due to the fact that collaborative learning has always been highlighted in science education; hence, these reviewed studies also preferred to employ Vygotsky's theory and activity theory as the theoretical foundations. Social interaction is a powerful catalyst for learning, as learning could be accelerated by observing and imitating experts and engaging in discussions with peers (Vygotsky 1978). From the viewpoint of neuroscience, the perspective that learning is social is also supported by neural circuits linking to perception and action (Meltzoff et al. 2009). The frequent social interactions in the learning environments of SGs often 
produce significant learning benefits as students are enabled to interact with each other in the virtual world without any constraints.

In the recent years, a broad set of cognitive and affective capabilities, such as being able to solve complex problems, to think critically about tasks, to effectively communicate with others, and to work in collaboration with others, have been identified and highlighted as "21st century skills" for modern citizens (National Research Council 2011). Furthermore, it has been advocated that these skills may be developed through high-quality science instruction (National Research Council 2010). As revealed in this study, although the majority of the learning goals of the SGs used in the reviewed empirical studies focused on student knowledge construction or problem-solving ability, a variety of other learning goals (for example, collaboration skills) have also been considered when designing SGs during the last decade. To promote students' development of 21 st century skills, the use of SGs may be helpful. Therefore, it is suggested that further research should aim to develop SGs that focus on developing learners' 21st century skills, such as complex problem-solving ability, critical thinking, effective communication ability and collaboration skills, and to examine the effectiveness of these SGs.

It has likewise been advocated that SGs can serve as powerful educational tools if used appropriately (e.g. Alessi and Trollip 2001). In other words, the pedagogical roles SGs may play should be highlighted. According to the findings of this study, the main pedagogical roles that SGs fill are either serving as a "learning environment" that provides learning contexts for complete science learning or serving as an "instructional tool" that is viewed as a learning activity within the whole instructional unit. Moreover, SGs have also been used to conduct formative assessments in recent years. This suggests that SGs may play various roles in improving students' science learning, and that science instructors should be sensible to the pedagogical role of a given SG used in a given science class. In that way, the SG can be used as effectively as possible to promote students' science learning.

This study also demonstrates that the majority of the SG-related studies focused on cognitive outcomes as a part of or as the only research outcomes and that relatively fewer studies explored students' affective outcomes or learning processes. These results are consistent with those of several previous studies by Li and Tsai (2013) and Connolly et al. (2012). However, science learning consists of more than mere knowledge acquisition, a fact that suggests future research should focus not only on participants' cognitive learning outcomes but also on their learning processes and affective aspects is obtained. To this end, the use of qualitative methods in further research will be helpful.

\section{Conclusions}

In the past, the term serious game was usually used to refer specifically to a game that was initially developed for training and education, in contrast to a commercial game created for entertainment (Connolly et al. 2012). However, we suggest that 
serious game has achieved a broader definition now as the number of studies that employ commercial games to facilitate the occurrence of learning has increased (e.g. Masson et al. 2011). Gee (2008) has argued that the human mind works just like a simulator; good video games are a perfect metaphor for the human mind and are a good place to study and produce human thinking and learning. In addition, in the book What Video Games Have to Teach Us About Learning and Literacy, Gee provided many examples of how good video games (commercial games) encourage learning and thinking (Gee 2003), Namely, video games provide contexts in where we can exercise the human mind and playing good video games in itself is a process of thinking and learning. Similarly, other researchers took some existing video games and simulations as examples to clarify that entertainment-oriented games not intended to teach can be useful for educational purposes under the right conditions (Squire 2003; Squire and Steinkuehler 2014). It turns out that what matters is not the initial purpose for developing a game, but the way that the game is used and how it supports learning. Therefore, in the present study, serious games are defined in a broader way to indicate video games of any type, as long as they were used for educational purposes.

Since the use of SGs in science education has attracted increased attention in the past decade, it is important to know what researches have been done and how they have been conducted thus far. Hence, this study was conducted to systematically review the empirical studies on the use of serious games in science education published from 2002 to 2013. With the use of the SCI and SSCI databases and the coding scheme developed in this study, several significant research trends were revealed. These research trends included the following: (1) a surge of interest in the use of serious games in science education was revealed during 2002-2013; (2) adventure/role-playing games were the most popular game type among the serious games used in the reviewed empirical studies; (3) knowledge construction was the major learning goal of those serious games used in science educational settings; (4) most of the reviewed studies were concerned with interdisciplinary learning; (5) relatively fewer studies explicitly introduced the educational theoretical foundations for using serious games in science education or the instructional strategies coupled with the use of serious games; (6) quantitative research designs constituted the most commonly used research approach and (7) a majority of the reviewed studies focused on investigating the effectiveness of serious games from the perspective of cognitive outcomes. This study may provide science educators, science instructors and serious game designers with integrated insights into the use of serious games in science education from different dimensions. To make effective use of serious games in science education, collaborations among science educators, science instructors and serious game designers will be a crucial but challenging issue.

Acknowledgement The authors gratefully acknowledge the sponsorship from the Ministry of Science and Technology of Taiwan, under the project number NSC 100-2511-S-018-014 and 101-2511-S-018004-MY3. 


\section{References}

Abt, C. (1970). Serious games. New York: The Viking Press.

Alessi, S. M., \& Trollip, S. R. (2001). Multimedia for learning: methods and development (3rd ed.). Boston: Allyn \& Bacon.

Annetta, L. A. (2008). Serious educational games: From theory to practice. Rotterdam: Sense Publishers.

Annetta, L. A., \& Cheng, M.-T. (2008). Why educational video games? In L. A. Annetta (Ed.), Serious educational games (pp. 1-11). Rotterdam: Sense Publishers.

Annetta, L. A., Mangrum, J., Holmes, S., Collazo, K., \& Cheng, M.-T. (2009a). Bridging reality to virtual reality: Investigating gender effects and students engagement on learning through video game play in an elementary school classroom. International Jornal of Science Education, 31(8), 1091-1113.

Annetta, L. A., Minogue, J., Holmes, S. Y., \& Cheng, M.-T. (2009b). Investigating the impact of video games on high school students' engagement and learning about Genetics. Computers \& Education, $53,74-85$.

Barab, S., Thomas, M., Dodge, T., Carteaux, R., \& Tuzun, H. (2005). Making learning fun: Quest Atlantis, a game without guns. Educational Technology Research and Development, 53(1), 86-107.

Brown, E., \& Cairns, P. (2004). A grounded investigation of game immersion. Paper presented at the CHI '04 extended abstracts on Human factors in computing systems. ACM Press. pp.1297-1300, Vienna, Austria.

Cheng, M.-T., \& Annetta, L. (2012). Students' learning outcomes and learning experiences through playing a Serious Educational Game. Journal of Biological Education,. doi:10.1080/00219266. 2012.688848.

Cheng, M.-T., Annetta, L. A., Folta, E., \& Holmes, S1. Y. (2011). Drugs and the Brain: Learning the impact of methamphetamine abuse on the brain through virtual brain exhibit in the museum. International Journal of Science Education, 33(2), 299-319.

Cheng, M.-T., She, H.-C., \& Annetta, L. A. (2014a). Game immersion experience: Its hierarchical structure and impact on game-based science learning. Journal of Computer Assisted learning,. doi:10.1111/jcal.12066.

Cheng, M.-T., Su, T., Huang, W.-Y., \& Chen, J.-H. (2014b). An educational game for learning human immunology: What do students learn and how do they perceive? British Journal of Educational Technology, 45(5), 820-833. doi:10.1111/bjet.12098.

Chung, I. H., \& Wu, Y. T. (2011). Digital educational games in science learning: A review of empirical research edutainment technologies. In M. Chang, W. Y. Hwang, M. P. Chen, \& W. Müller (Eds.), Educational games and virtual reality/augmented reality applications (Vol. 6872, pp. 512-516). Heidelberg: Springer.

Clark, D. B., Nelson, B. C., Sengupta, P., \& D' Angelo, C. (2009). Rethinking science learning through digital games and simulations: Genres, examples, and evidence. Washington DC: National Research Council.

Connolly, T. M., Boyle, E. A., MacArthur, E., Hainey, T., \& Boyle, J. M. (2012). A systematic literature review of empirical evidence on computer games and serious games. Computers \& Education, 59(2), 661-686. doi:10.1016/j.compedu.2012.03.004.

Dede, C. (2009). Immersive interfaces for engagement and learning. Science, 323(5910), 66-69. doi:10. 1126/science.1167311.

Echeverría, A., García-Campo, C., Nussbaum, M., Gil, F., Villalta, M., Améstica, M., \& Echeverría, S. (2011). A framework for the design and integration of collaborative classroom games. Computers \& Education, 57(1), 1127-1136. doi:10.1016/j.compedu.2010.12.010.

Entertainment Software Association. (2013). Essential facts about the computer and video game industry. Retrieved May 14, 2013, from http://www.theesa.com/facts/pdfs/esa_ef_2013.pdf.

Gee, J. P. (2003a). High Score Education: Games, not school, are teaching kids to think. Wired, 11(5). Retrieved from: http://www.wired.com/wired/archive/11.05/view.html.

Gee, J. P. (2003b). What video games have to teach us about learning and literacy. New York: Palgrave.

Gee, J. P. (2008). Good videogames, the human mind, and good learning. In T. Willoughby \& E. Wood (Eds.), Children's learning in a digital world (pp. 40-63). Oxford: Blackwell Publishing Ltd.

Hwang, G.-J., \& Wu, P.-H. (2012). Advancements and trends in digital game-based learning research: a review of publications in selected journals from 2001 to 2010. British Journal of Educational Technology, 43(1), E6-E10. doi:10.1111/j.1467-8535.2011.01242.x. 
Li, M.-C., \& Tsai, C.-C. (2013). Game-based learning in science education: A review of relevant research. Journal of Science Education and Technology, 22(6), 877-898. doi:10.1007/s10956-0139436-X.

Masson, M. E. J., Bub, D. N., \& Lalonde, C. E. (2011). Video-game training and naïve reasoning about object motion. Applied Cognitive Psychology, 25(1), 166-173. doi:10.1002/acp.1658.

Meltzoff, A. N., Kuhl, P. K., Movellan, J., \& Sejnowski, T. J. (2009). Foundations for a new science of learning. Science, 325(5938), 284-288. doi:10.1126/science.1175626.

Milgram, P., \& Kishino, F. (1994). A taxonomy of mixed reality visual displays. IEICE Transactions on Information Systems, 77(12), 1321-1329.

Miller, L. M., Chang, C.-I., Wang, S., Beier, M. E., \& Klisch, Y. (2011). Learning and motivational impacts of a multimedia science game. Computers \& Education, 57, 1425-1433.

National Research Council. (2010). Exploring the intersection of science education and 21st century skills: A workshop summary. Washington, DC: National Academies Press.

National Research Council. (2011). Assessing 21st century skills: Summary of a workshop. Washington, DC: National Academy Press.

Papastergiou, M. (2009). Digital game-based learning in high school computer science education: Impact on educational effectiveness and student motivation. Computers \& Education, 52(1), 1-12. doi:10. 1016/j.compedu.2008.06.004.

Paraskeva, F., Mysirlaki, S., \& Papagianni, A. (2010). Multiplayer online games as educational tools: Facing new challenges in learning. Computers \& Education, 54(2), 498-505. doi:10.1016/j. compedu.2009.09.001.

Prensky, M. (2001). Digital game-based learning. New York: McGraw-Hill.

Pursell, D. P. (2009). Adapting to student learning styles: Engaging students with cell phone technology in organic chemistry instruction. Journal of Chemical Education, 86(10), 1219. doi:10.1021/ ed086p1219.

Radoff, J. (2011). Game on: Energize your business with social media games. Indianapolis, IN: Wiley Publishing.

Sánchez, J., \& Olivares, R. (2011). Problem solving and collaboration using mobile serious games. Computers \& Education, 57(3), 1943-1952. doi:10.1016/j.compedu.2011.04.012.

Squire, K. D. (2003). Video games in education. International Journal of Intelligent Games \& Simulation, 2(1), 49-62.

Squire, K. D., Narnett, M., Grant, J. M., \& Higginbotham, T. (2004). Electromagnetism supercharged! learning physics with digital simulation games. Paper presented at the 6th international conference on learning sciences, Santa Monica, CA. http:/www.educationarcade.org/files/articles/ Supercharged/SuperchargedResearch.pdf.

Squire, K. D., \& Steinkuehler, C. (2014). Videogames and learning. In K. Sawyer (Ed.), Cambridge handbook of the learning sciences (2nd ed., pp. 377-396). New York, NY: Cambridge University Press.

Susi, T. (2007). Serious games: An overview. Sweden: School of Humanities and Informatics, University of Skövde.

Vygotsky, L. (1978). Minds in society: the development of higher psychological processes. Cambridge, MA: Harvard University Press.

Young, M. F., Slota, S., Cutter, A. B., Jalette, G., Mullin, G., Lai, B., \& Yukhymenko, M. (2012). Our princess is in another castle: A review of trends in serious gaming for education. Review of Educational Research, 82(1), 61-89. doi:10.3102/0034654312436980.

Zyda, M. (2005). From visual simulation to virtual reality to games. Computer, 38(25), 25-32.

Meng-Tzu Cheng is an Associate Professor of Science Education in the Department of Biology at the National Changhua University of Education. Her research interests mainly include the consequences of game experience and understanding how ICTs and serious educational games influence middle school students' biology learning.

Jhih-Hao Chen is a middle school Biology Teacher in Taiwan. 
Sheng-Ju Chu is a Graduate Student in the Department of biology at the National Changhua University of Education.

Shin-Yen Chen is a Graduate Student in the Department of biology at the National Changhua University of Education. 